\title{
Improvement of light-harvesting and electron injection efficiencies by lithium ion in D149-sensitized nanocrystalline $\mathrm{TiO}_{2}$ films
}

Akihiro Namekawa, Ryuzi Katoh*

Department of Chemical Biology and Applied Chemistry, College of Engineering, Nihon

University, Koriyama, Fukushima 963-8642, Japan

*Corresponding author. E-mail: rkatoh@chem.ce.nihon-u.ac.jp

\begin{abstract}
The effect of $\mathrm{Li}$ ion on the light-harvesting and electron injection efficiencies of D149-sensitized nanocrystalline $\mathrm{TiO}_{2}$ films was studied. Absorption spectra shifted toward the long-wavelength region when films were immersed in a $\mathrm{Li}$ ion solution, indicating that $\mathrm{Li}$ ion enhanced light-harvesting efficiency. We also found that electron injection efficiency was dramatically enhanced by $\mathrm{Li}$ ion. These observations indicate that it is essential to incorporate $\mathrm{Li}$ ion in the electrolyte of D149-sensitized solar cell devices to improve their performance.
\end{abstract}

\section{Introduction}

Dye-sensitized solar cells (DSCs) have been extensively studied as an attractive new class of solar cells [1-3]. Compared with other types of solar cells (e.g., Si-based solar cells), DSCs have several advantages, including low cost, flexibility, color availability, and potential for indoor applications [1-3]. Although DSCs have the potential for practical applications, they are unavailable as commercial products, because device performance and long-term stability have not yet been optimized. To date, the official U.S. National Renewable Energy Laboratory record for solar light-to-energy conversion efficiency $(\eta)$ for DSCs is $11.9 \%$ [4].

To improve device performance, the primary processes of DSCs have been extensively studied. DSCs consist of two electrodes (a dye-sensitized electrode and a counter electrode) with an electrolyte solution sandwiched between them. The dye-sensitized electrode consists of a nanoporous, nanocrystalline $\mathrm{TiO}_{2}$ film with dye molecules chemically adsorbed on the surface. The counter electrode consists of platinum nanoparticles on a conducting electrode. The electrolyte solution contains a redox mediator, such as $\mathrm{I}^{-} / \mathrm{I}_{3}{ }^{-}$. When the dye-sensitized electrode is irradiated with light, the excited 
sensitizing dye injects electrons into the nanocrystalline $\mathrm{TiO}_{2}$ film; it is these conducting electrons that are collected and used as electricity. The oxidized dye molecules are reduced by the redox mediator through the counter electrode. Optimization of such primary processes is a key for the development of high-performance DSC devices.

Because of its importance, the electron injection process has been extensively studied [5-8]. However, reported results are not always consistent; thus, a comprehensive model has not yet been established. Recently, Haque et al. [9] and Juozapavicius et al. [10] pointed out that the electron injection dynamics of whole complete cells is much different from that of a model system such as an isolated dye-sensitized electrode. This observation suggests that additives in the electrolyte also would play an important role in affecting electron injection processes. Understanding such synergy effects is essential for a complete understanding of primary processes in DSCs.

The effect of adding various additives (Li ion, 4-tert-butylpyridine, guanidinium thiocyanate) to the electrolyte in DSCs to control their performance has been examined [13]. Li ions improve short-circuit current $\left(J_{S C}\right)$, but their addition often results in a decrease in open-circuit voltage $\left(V_{O C}\right)$. Such trade-off phenomena have been explained by energy shifts of the conduction band edge $\left(E_{\mathrm{CB}}\right)$ of $\mathrm{TiO}_{2}$ induced by intercalation of $\mathrm{Li}$ ions into the $\mathrm{TiO}_{2}$ lattice [2]. The mechanism of the enhancement of $J_{S C}$ has been confirmed by the fact that the electron injection efficiency $\left(\Phi_{\text {inj }}\right)$ increases upon addition of Li ions [11-13]. Moreover, addition of $\mathrm{Li}$ ions induces changes in absorption spectra. For the Ru complex $\left[R u(d e e b)(b p y) 2_{2}{ }^{2+}\right.$, absorption spectra slightly shift toward the long-wavelength region upon addition of Li ions [11]. For organic dyes, remarkable changes in absorption spectra have been observed [12].

D149 (Figure 1) is a promising sensitizing dye, and DSC devices based on this dye show a high solar light-to-energy conversion efficiency $(\eta>8 \%)[14,15]$. To understand the origin of the high performance, various characterization methods have been employed $[10,16-19]$. However, in reality, the origin is still controversial because the synergy effect between a sensitizing dye and the electrolyte solution plays an important role. One remarkable effect is that the onset wavelength of the incident photon-to-current conversion efficiency (IPCE) is longer than that of the absorption spectra of D149 dyes adsorbed on $\mathrm{TiO}_{2}$ recorded under ambient conditions [14]. This suggests that absorption spectral change is induced by the interaction between a dye and some of the additives in the electrolyte solution. Although spectral change induced by aggregation of dyes has been frequently 
argued, there are no strong experimental evidences. The other important fact is that solid-state D149-sensitized DSC devices exhibit relatively low performance [20], whereas optimized liquid-based D149-sensitized DSC devices show high performance ( $\eta>8 \%)$. This difference suggests that $\Phi_{\text {inj }}$ is affected by the interaction with some of the additives in the electrolyte solution. It is apparent that synergy effect is key factor for the development of high performance DSCs. In this context, detail study of D149, which is a prototype of organic sensitizing dyes, is important. Thus, we studied the effect of $\mathrm{Li}$ ion on the light-harvesting and electron injection efficiencies in $\mathrm{D} 149$-sensitized nanocrystalline $\mathrm{TiO}_{2}$ films.

\section{Experimental}

An organic paste containing $\mathrm{TiO}_{2}$ nanoparticles (Ti-Nanoxide HT/SP; Solaronix) was screen-printed onto glass slides, and the printed substrates were calcined for $1 \mathrm{~h}$ at 800 $K$ to afford highly transparent nanocrystalline films with an area of $1.5 \mathrm{~cm}^{2}(1.5 \mathrm{~cm} \times 1 \mathrm{~cm})$ and a thickness of about $5 \mu \mathrm{m}$. $\mathrm{Al}_{2} \mathrm{O}_{3}$ films were prepared by spin-coating an $\mathrm{Al}_{2} \mathrm{O}_{3}$ slurry (ALAP15WT\%-X480, NanoTek) onto glass slides. After calcination for $1 \mathrm{~h}$ at $800 \mathrm{~K}$, $\sim 1$ - $\mu \mathrm{m}$-thick films were obtained. D149 (Figure 1, Aldrich) was dissolved in ethanol. The nanocrystalline $\mathrm{TiO}_{2}$ films were immersed in the dye solution for $20 \mathrm{~h}$, so that the dye could adsorb onto the semiconductor surface. The films then were rinsed with ethanol and dried in air. Absorption spectra of the films were measured with an absorption spectrometer (V-670, JASCO).

Time-resolved microwave conductivity (TRMC) measurements were carried out with homemade TRMC equipment [21]. Microwaves were generated by an oscillator based on a Gunn diode (MGS-15B, $200 \mathrm{~mW}$; Nakadai). The oscillator was equipped with a varactor diode, which was used to tune the frequency of the microwaves from 8.5 to $10 \mathrm{GHz}$ (X-band). The microwaves traveled toward the sample cavity through a circulator. The second harmonic $\left(532 \mathrm{~nm}\right.$ ) of a $\mathrm{Nd}^{3+}$ :YAG laser (Surelite II, HOYA Continuum) was employed for excitation, and the repetition rate of the laser was $10 \mathrm{~Hz}$. Reflected microwaves were detected with a diode (IN23WE, NEC). The photocurrent from the detector was amplified with an amplifier (DHPVA-100, Femto), and signals were processed with a digital oscilloscope (TDS5032, Tektronix) and analyzed with a computer. The time resolution of the equipment was about 20 ns.

Transient absorption (TA) measurements were carried out with the $\mathrm{Nd}^{3+}$ :YAG laser described above. The second harmonic $(532 \mathrm{~nm})$ of the laser was used for excitation, and a halogen lamp (100 W) was used as the probe light source. The repetition rate of the laser 
was $10 \mathrm{~Hz}$. The light transmitted through the sample films was detected with an InGaAs photodiode (DET10C, Thorlabs) after being dispersed with a monochromator (CM110, Spectra Products). The photocurrent from the detector was amplified with an amplifier (DHPVA-100, Femto), and signals were processed with a digital oscilloscope (TDS380, Tektronix) and analyzed with a computer. The DC offset of the photocurrent from the detector was subtracted by using the AC-coupled mode of the amplifier; therefore small absorbance changes $\left(<10^{-4}\right)$ could be detected. The time resolution of the system was about $20 \mathrm{~ns}$. The intensity of the laser pulse was measured with a pyroelectric energy meter (PE25-C, Ophir).

\section{Results and discussion}

\subsection{Effect of aggregation}

The onset wavelength of the absorption spectrum of $\mathrm{D} 149 / \mathrm{TiO}_{2}$ was longer than that of D149 in ethanol solution (Figure 1). This is consistent with Horiuchi et al.'s [14] original paper on D149-sensitized DSCs. In that paper and later papers [18, 22], the spectral red shift was claimed to be due to aggregate formation; a theoretical calculation was also reported [23]. In our opinion, the aggregate formation model proposed by these researchers is not supported by direct experimental evidence.

A possible explanation for the red shift is the interaction between the dye and the semiconductor. Rajh et al. [24] observed that the absorption spectra of dyes adsorbed on $\mathrm{TiO}_{2}$ sometimes change due to charge-transfer interaction with $\mathrm{TiO}_{2}$. Here, we compared the absorption spectrum of D149 adsorbed on another semiconductor having a higher band gap energy $\left(\mathrm{Al}_{2} \mathrm{O}_{3}\right)$ with the absorption spectrum of $\mathrm{D} 149 / \mathrm{TiO}_{2}$ (Figure 1). We found no significant difference between the spectra, indicating that the red shift of the absorption spectra is not due to a charge-transfer interaction between $\mathrm{TiO}_{2}$ and $\mathrm{D} 149$. The difference in the short-wavelength region is probably due to the difference of light scattering between the $\mathrm{TiO}_{2}$ and the $\mathrm{Al}_{2} \mathrm{O}_{3}$ films.

To clarify the effect of aggregation on the absorption spectra, the effect of co-adsorbate should be considered. Chenodeoxycholic acid (CDCA) acts as a co-adsorbate; thus, CDCA can be used to reduce the density of a dye on the surface of an adsorbent. Yaguchi et al. [25] found that the shape of the absorption spectrum of eosin $Y$ adsorbed on $\mathrm{TiO}_{2}$ strongly depends on the presence of CDCA and the concentration of the dye in solution. This finding clearly indicates that dye aggregation can be controlled by the presence of CDCA and dye concentration. Sobuś et al. [19] studied the effect of addition of 
CDCA on the absorption spectrum of $\mathrm{D} 149 / \mathrm{TiO}_{2}$ and found that the absorption spectrum was not sensitive to the density of the dye on the surface of $\mathrm{TiO}_{2}$. We carried out similar experiments and obtained similar results (data not shown). In addition to the effect of co-adsorbates, we also evaluated the effect of dye loading (Figure 2). Absorbance decreased with decreasing concentration of dye in the solutions used to prepare the $\mathrm{TiO}_{2}$ films, indicating a decrease in dye concentration on the $\mathrm{TiO}_{2}$ surface (Figure 2a). Absorption spectra normalized to their peak intensities show that the spectra are not sensitive to the density of the dye on the surface of the $\mathrm{TiO}_{2}$ (Figure $2 \mathrm{~b}$ ). The small difference in the short-wavelength region is probably due to light scattering by the $\mathrm{TiO}_{2}$ films. This result together with the effect of CDCA co-adsorption suggests that aggregation of D149 dyes on the surface of $\mathrm{TiO}_{2}$ is not the major reason for the red shift of the absorption spectrum of $\mathrm{D} 149 / \mathrm{TiO}_{2}$ compared with that of D149 in ethanol solution.

At present, we have no unambiguous explanation for the red shift. A possible interpretation is that the molecular structures in solution and on the semiconductor surface are different. Recently, El-Zohry et al. [18] reported that photoisomerization of D149 in solution is suppressed when dyes are adsorbed on semiconductor films. This finding implies that the structure of $\mathrm{D} 149$ is restricted on the $\mathrm{TiO}_{2}$ surface.

\subsection{Effect of additives in electrolyte}

As mentioned above, the onset wavelength of the absorption spectrum of $\mathrm{D} 149 / \mathrm{TiO}_{2}$ was longer than that of D149 in ethanol solution. Strangely, this onset wavelength is shorter than that of the IPCE spectrum [14]. According to the literature, the onset wavelength of the absorption spectrum is about $700 \mathrm{~nm}$ [14], which is similar to that observed in the present study (Figure 1). In contrast, the onset wavelength of the IPCE spectrum is about $750 \mathrm{~nm}$ [14]. This difference implies the presence of a specific interaction between the dye and additives in the electrolyte solution.

Absorption spectra of D149 are sensitive to solvent [17,18], and the slight red shift of the spectrum of $\mathrm{D} 149 / \mathrm{TiO}_{2}$ in acetonitrile (ACN) compared to that in air is due to a solvent effect (Figure 3). However, in Figure 3, no significant difference between the $\mathrm{I}^{-}$and $\mathrm{Bmim}^{+}$ spectra is apparent, suggesting that only the solvent effect of ACN is operating. A relatively large effect was observed when $\mathrm{Li}^{+}$ions were added to the electrolyte solution. This result indicates that $\mathrm{Li}$ ions in the electrolyte solution of DSC devices are the major reason for the difference between the onset wavelengths of the IPCE and absorption spectra of D149/TiO 2 under ambient conditions. 
The effect of $\mathrm{Li}$ ions on absorption spectra has been reported for a Ru complex [11] and coumarin dye NKX2311 [12]. Although the origin of the spectral shift is not yet clear, on the basis of spectroscopic results and a computational calculation, Furube et al. proposed that the shift was due to formation of a complex between a $\mathrm{Li}$ ion and a dye molecule [12]. For NKX2311, the spectral change upon addition of Li ions was remarkably large, whereas only a peak shift was observed in the absorption spectra in the present study. Thus, the peak shift in Figure 3 is unlikely due to formation of a complex between $\mathrm{Li}$ ion and a dye molecule.

Coulombic interactions induced by Li ions are probably responsible for the peak shift. Lithium ions can intercalate into the $\mathrm{TiO}_{2}$ lattice, causing the $\mathrm{TiO}_{2}$ surface to become positively charged. According to a study of the Stark effect on D149 adsorbed onto flat $\mathrm{TiO}_{2}$ films, the absorption spectrum shifts toward the long-wavelength region when $\mathrm{TiO}_{2}$ is positively charged [26]. Thus, it is likely that the red shift induced by addition of $\mathrm{Li}$ ions is due to a Stark effect induced by $\mathrm{Li}$ ions in the $\mathrm{TiO}_{2}$ lattice.

As shown above, adding $\mathrm{Li}$ ions to the electrolyte of a DSC is essential to achieve high light-harvesting efficiency. In this context, it is interesting to compare IPCE spectra for various conditions. The onset wavelength in the IPCE spectrum of $\mathrm{D} 149 / \mathrm{TiO}_{2}$ with $\mathrm{Li}$ ions in the electrolyte is $750 \mathrm{~nm}$ [14], whereas the IPCE onset wavelength for D149/ZnO without Li ions in the electrolyte is $700 \mathrm{~nm}$ [22]. For a solid-state DSC based on a hole transport polymer, the IPCE onset wavelength was about $650 \mathrm{~nm}$ [20]. Although some conditions in these studies are different, the significant difference in the onset wavelengths of the IPCE spectra is probably due to $\mathrm{Li}$ ions.

\subsection{Electron injection efficiency}

The performance of solid-state D149-sensitized DSC devices is considerably lower than that of their liquid-based counterparts [20]. This implies that a primary process, in particular the electron injection process, is strongly affected by additives in the electrolyte of a liquid-based device. We studied the effect of $\mathrm{Li}$ ions on the electron injection efficiency ( $\left.\Phi_{\text {inj }}\right)$ of $\mathrm{D} 149 / \mathrm{TiO}_{2} . \Phi_{\text {inj }}$ is affected by additives such as $\mathrm{Li}$ ions and 4-tert-butylpyridine (tBP) in the electrolyte solution [8,11-13]. TRMC is useful for evaluating the absolute value of $\Phi_{\text {inj }}$ [27]. We note that the effect of $\mathrm{Li}$ ions is difficult to study by TRMC because of efficient absorption of microwave power by solvent molecules. Thus, TRMC was used to evaluate the absolute value of $\Phi_{\text {inj }}$ for dried films, and the effect of $\mathrm{Li}$ ions was studied through 
conventional optical TA spectroscopy.

TRMC is a type of TA spectroscopy using microwaves as a probe to measure the conductivity $(\sigma)$ of mobile charges produced by pulsed light excitation [27]. The absorption of microwave power $(-\Delta P / P)$ can be expressed as

$$
\left(\frac{-\Delta P}{P}\right)=K \sigma=K^{\prime} \mu N_{\mathrm{e}}
$$

where $K$ and $K^{\prime}$ are a constant, $\mu$ is the mobility of the charge carriers, and $N_{\mathrm{e}}$ is the number of electrons presented. $N_{\mathrm{e}}$ can be expressed as

$$
N_{\mathrm{e}}=I_{\mathrm{ex}}\left(1-10^{-A}\right) \Phi_{\text {inj }}
$$

where $l_{\mathrm{ex}}$ is the intensity of the excitation light, $A$ is the absorbance of the excitation light by a sample specimen at the excitation wavelength.

Upon pulsed laser excitation, $-\Delta P / P$ shows a maximum and then decreases due to charge recombination and/or trapping processes. Thus, $\Phi_{\text {inj }}$ can be evaluated from the maximum value $(-\Delta P / P)_{\text {MAX }}$. Since the value of $(-\Delta P / P)_{\text {MAX }}$ in $\mathrm{TiO}_{2}$ nanoparticles is sensitive to the density of electrons [28], $(-\Delta P / P)_{\operatorname{MAX}}$ can be expressed as

$$
\left(\frac{-\Delta P}{P}\right)_{\mathrm{MAX}}=K^{\prime}(d) \mu I_{\mathrm{ex}}\left(1-10^{-A}\right) \Phi_{\mathrm{inj}}
$$

where $K^{\prime}(d)$ is a density-dependent constant.

To evaluate the absolute value of $\Phi_{\mathrm{inj}}$, a standard sample is required. Thus, $\mathrm{N} 719 / \mathrm{TiO}_{2}$, for which $\Phi_{\mathrm{inj}}$ is unity [27], was measured under the same experimental conditions as those for $\mathrm{D} 149 / \mathrm{TiO}_{2}$. Thus, we plot $(-\Delta P / P)_{\mathrm{MAX}}$ divided by $\left[l_{\mathrm{ex}}\left(1-10^{-A}\right) \Phi_{\mathrm{inj}}\right]$ as a function of the density of generated electrons, i.e., ((excitation density) $\left.\Phi_{\text {inj }}\right)$ as shown in Fig. 4. For these plots, values of $A=3.9$ for $\mathrm{D} 149 / \mathrm{TiO}_{2}$ and $A=1$ for $\mathrm{N} 719 / \mathrm{TiO}_{2}$ were used. $(-\triangle P / P)_{\operatorname{MAX}} /\left[I_{\mathrm{ex}}\left(1-10^{-A}\right) \Phi_{\mathrm{in}}\right]$ increased with increasing density of generated electrons. According to previous studies, this tendency can be attributed to a trap-filling effect [28]. At low $l_{\text {ex }}$, all generated electrons are effectively trapped, and their effective mobility becomes 
very small. The number of mobile electrons increases with increasing $l_{\mathrm{ex}}$ because the traps are "filled" with other electrons; therefore, a large TRMC signal was observed.

Using the value $\Phi_{\mathrm{inj}}=1$ for $\mathrm{N} 719$, we estimate $\Phi_{\mathrm{inj}}=0.55$ for D149. We note that the electron injection efficiency obtained $\left(\Phi_{\text {inj }}=0.55\right)$ is smaller than the maximum IPCE value for DSC devices (85\%) [14], suggesting that interaction with the electrolyte plays an important role in realizing high $\Phi_{\text {inj. }}$.

We have studied $\Phi_{\text {inj }}$ for various dye-sensitized nanocrystalline films [8]. We found that the energy level of the lowest unoccupied molecular orbital (LUMO) of the dye is the most important parameter influencing the value of $\Phi_{\text {inj: }}$ high values of $\Phi_{\text {inj }}$ are observed if the energy level of the LUMO is located sufficiently higher than the energy of the conduction band edge $\left(E_{\mathrm{CB}}\right)$. Some dyes have relatively small $\Phi_{\text {inj }}$ values even when the LUMO level is sufficiently high, mainly due to aggregation. In this paper, we have established that aggregation is not important for $\mathrm{D} 149 / \mathrm{TiO}_{2}$; thus, $\Phi_{\text {inj }}$ was expected to be high. However, we determined $\Phi_{\text {inj }}=0.55$, suggesting that the LUMO level is not sufficiently high. As far as we know, information on the LUMO level of D149 is not available; therefore, in this paper, we do

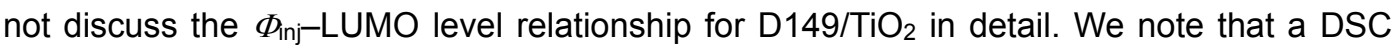
device based on $\mathrm{D} 149 / \mathrm{TiO}_{2}$ with no $\mathrm{tBP}$ in the electrolyte shows a high performance (tBP is widely used to enhance performance of conventional systems such as $\mathrm{N} 719 / \mathrm{TiO}_{2}$ ) [14]. Because addition of tBP to the electrolyte increases the $E_{C B}$ level, this implies that D149 has a low LUMO level relative to $E_{\mathrm{CB}}$.

Figure 5 shows TA spectra of $\mathrm{D} 149 / \mathrm{TiO}_{2}$ just after excitation in various environments. All measurements were carried out under the same optical geometry; therefore, signal intensity is proportional to the number of photoproducts if absorption coefficients are identical. The absorption spectrum of the D149 cation [16] is similar to the spectra in Figure 5. Thus, we assign the spectra in Figure 5 to the cation of the D149 dye; that is, the electron injection process can be studied by monitoring this absorption band. To eliminate the effect of high-density excitation, excitation light intensity was reduced; in this case, the absorbance change was proportional to $l_{\mathrm{ex}}$.

In Air, the absorption peak is located around $1300 \mathrm{~nm}$; in $\mathrm{ACN}$, the peak position shifts toward shorter wavelengths $(1250 \mathrm{~nm})$. The blue shift is probably due to a solvent effect. The TA spectrum in Bmim ${ }^{+}$is almost identical to that in Air, indicating no effect from ACN solvent. This is probably due to that bis(trifluoromethanesulfonyl)imide, which is 
counter anion of $\mathrm{Bmim}^{+}$, is selectively located around D149 cation. The absorbances in Air, $\mathrm{ACN}$, and $\mathrm{Bmim}^{+}$are almost the same, that means similar $\Phi_{\text {inj. }}$ In $\mathrm{I}^{-}$, the absorbance is slightly smaller than that in Air, suggesting that electron injection is suppressed by $\mathrm{I}$. We observed that the decay rate of TA signal in I- was faster than that in Air (data is not shown), suggesting that the reduction of D149 cation by I- occurs. Accordingly, fast reduction within the time-resolution of our TA-spectrometer is another possible reason for the decrease of TA signal. In Li solution, the TA signal increases dramatically, indicating enhancement of $\Phi_{\text {inj. }}$. Although it is difficult to estimate $\Phi_{\text {inj }}$ precisely because of possible change in absorption coefficient, the change in TA signal intensity is significantly high, suggesting that $\Phi_{\text {inj }}$ is almost unity. This clearly indicates that $\mathrm{Li}$ ions in electrolyte solution are essential for high-performance DSC devices based on D149.

Similar enhancement of $\Phi_{\mathrm{inj}}$ by $\mathrm{Li}$ ion addition has been observed for other dye-sensitized films such as ([Ru(deeb)(bpy) $\left.2_{2}{ }^{2+}\right]$ [11], [Ru(tcterpy)(NCS $\left.)_{3}\right]$ [13] and the coumarin dye NKX2311 [12]. The LUMO levels of these dyes are slightly lower than $E_{C B}$ under ambient conditions; therefore, under ambient conditions, $E_{C B}$ decreases upon addition of $\mathrm{Li}$ ions and higher electron injection efficiency can be realized. As mentioned above, the performance of solid-state D149-sensitized DSC devices is low [20], whereas optimized liquid-based D149-sensitized DSC devices show high performance ( $\eta>8 \%)$. This difference can be explained by the fact that there are no Li ions in the solid-state electrolyte.

\section{Conclusion}

The effect of $\mathrm{Li}$ ion on the absorption spectra and electron injection efficiency of $\mathrm{D} 149 / \mathrm{TiO}_{2}$ was studied. We have demonstrated that $\mathrm{Li}$ ion is essential for high-performance D149-based DSCs. Light-harvesting efficiency is enhanced due to the red shift of the absorption edge induced by $\mathrm{Li}$ ions, and electron injection efficiency is enhanced due to a lowering of $E_{\mathrm{CB}}$. Understanding this synergistic effect is essential for a complete understanding of the primary processes in DSCs.

\section{Acknowledgments}

This research was supported by SENTAN, JST.

\section{References}

[1] A. Hagfeldt, M. Grätzel, Chem. Rev. 95 (1995) 49.

[2] A. Hagfeldt, G. Boschloo, L. Sun, L. Kloo, H. Pettersson, Chem. Rev. 110 (2010) 6595.

[3] K. Kalyanasundaram, Dye-sensitized Solar Cells, EPFL Press, Lausanne, 2010. 
[4] http://www.nrel.gov/ncpv/images/efficiency_chart.jpg

[5] J. B. Asbury, E. Hao, Y. Wang, H. N. Ghosh, T. Lian, J. Phys. Chem. B 105 (2001) 4545.

[6] J. R. Durrant, S. A. Haque, E. Palomares, Chem. Commun. (2006) 3279.

[7] S. Ardo, G. J. Meyer, Chem. Soc. Rev. 38 (2009) 115.

[8] R. Katoh, A. Furube, J. Photochem. Photobiol. C 20 (2014) 1.

[9] S. A. Haque, E. Palomares, B. M. Cho, A. N. M. Green, N. Hirata, D. R. Klug, J. R. Durrant, J. Am. Chem. Soc. 127 (2005) 3456.

[10] M. Juozapavicius, M. Kaucikas, J. J. van Thor, B. C. O'Regan, J. Phys. Chem. C 117 (2013) 116.

[11] C. A. Kelly, G. J. Meyer, Cood. Chem. Rev. 211 (2001) 295.

[12] A. Furube, R. Katoh, K. Hara, T. Sato, S. Murata, H. Arakawa and M. Tachiya, J. Phys. Chem. B 109 (2005) 16406.

[13] R. Katoh, M. Kasuya, S. Kodate, A. Furube, N. Fuke, N. Koide, J. Phys. Chem. C 113 (2009) 20738. .

[14] T. Horiuchi, H. Miura, K. Sumioka, S. Uchida, J. Am. Chem. Soc.126 (2004) 12218.

[15] S. Ito, H. Miura, S. Uchida, M. Takata, K. Sumioka, P. Liska, P. Comte, P. Péchy, M. Grätzel, Chem. Commun. (2008) 5194.

[16] K. Oum, P. W. Lohse, O. Flender, J. R. Klein, M. Scholz, T. Lenzer, J. Du, T. Oekermann, Phys. Chem. Chem. Phys.14 (2012) 15429.

[17] M. Fakis, P. Hrobárik, E. Stathatos, V. Giannetas, P. Persephonis, Dyes Pigments 96 (2013) 304.

[18] A. El-Zohry, A. Orthaber, B. Zietz, J. Phys. Chem. C 116 (2012) 26144.

[19] J. Sobuś, J. Karalczak, D. Komar, J. A. Anta, M. Ziółek, Dyes Pigments 113 (2015) 692.

[20] W. H. Howie, F. Claeyssens, H. Miura, L. M. Peter, J. Am. Chem. Soc. 130 (2008) 1367.

[21] R. Katoh, A. Furube, K. Yamanaka, T. Morikawa, J. Phys. Chem. Lett. 1 (2010) 3261.

[22] Y. Sakuragi, X-F. Wang, H. Miura, M. Matsui, T. Yoshida, J. Photochem. Photobiol. A 216 (2010) 1.

[23] M. Pastore, F. De Angelis, ACS Nano 4 (2009) 556.

[24] T. Rajh, L. X. Chen, K. Lukas, T. Liu, M. C. Thurnauer, D. M. Tiede, J. Phys. Chem. B 106 (2002) 10543.

[25] K. Yaguchi, A. Furube, and R. Katoh, Chem. Phys. Lett. 551 (2012) 96.

[26] U. B. Cappel, S. M. Feldt, J. Schöneboom, A. Hagfeldt, G. Boschloo, J. Am. Chem. Soc. 132 (2010) 9096.

[27] R. Katoh, A. Huijser, K. Hara, T. J. Savenije, and L. D.A. Siebbeles, J. Phys. Chem. C 111 (2007) 10741.

[28] J. E. Kroeze, T. Savenije, J. M. Warman, J. Am. Chem. Soc. 126 (2004) 7608. 


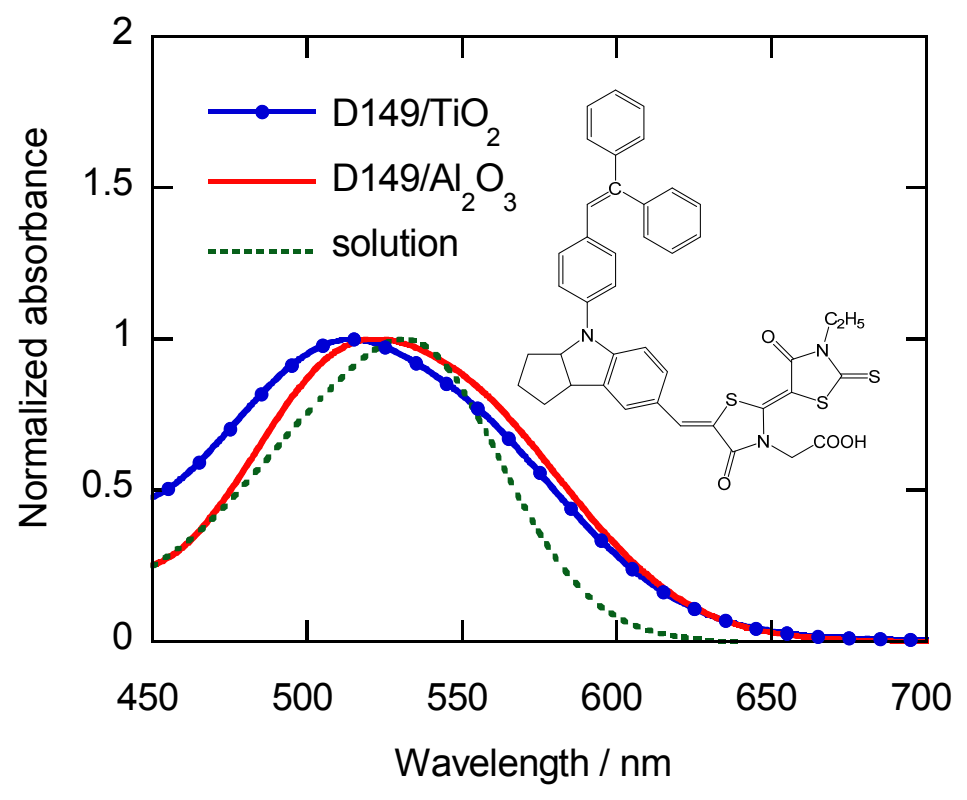

Fig. 1

Absorption spectra of D149 in ethanol solution and of D149 adsorbed on nanocrystalline $\mathrm{TiO}_{2}\left(\mathrm{D} 149 / \mathrm{TiO}_{2}\right)$ and $\mathrm{Al}_{2} \mathrm{O}_{3}\left(\mathrm{D} 149 / \mathrm{Al}_{2} \mathrm{O}_{3}\right)$ films. 

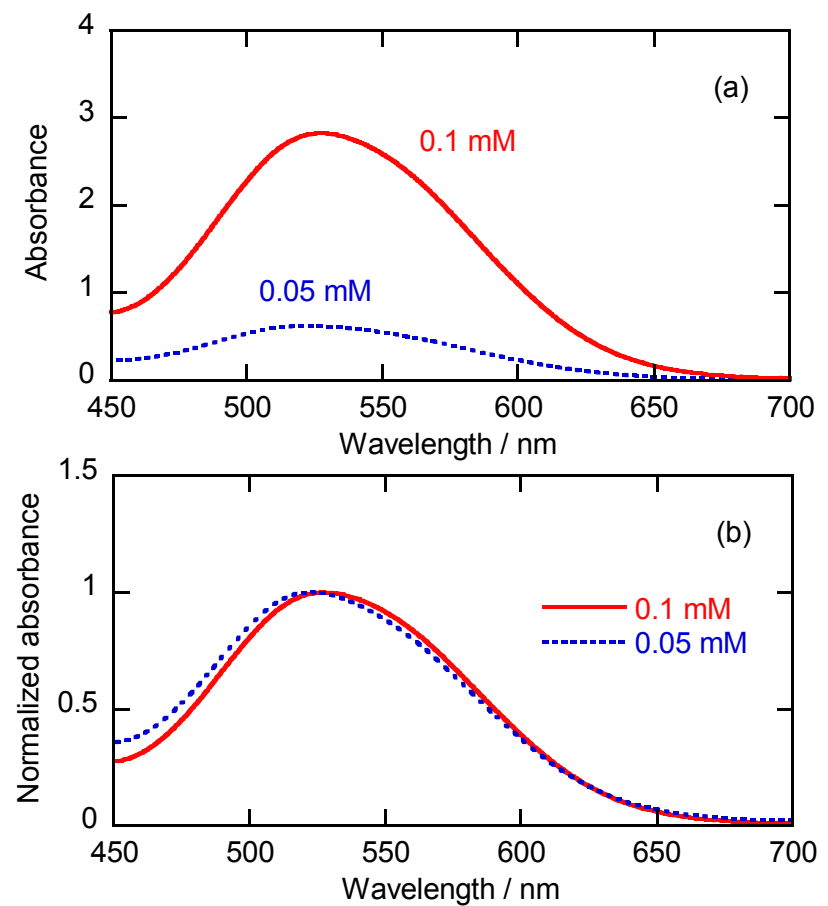

Fig. 2

Absorption spectra of $\mathrm{D} 149 / \mathrm{TiO}_{2}$ prepared from solutions with different dye concentrations (0.1 and $0.05 \mathrm{mM})(\mathrm{a})$ and their normalized spectra (b). 


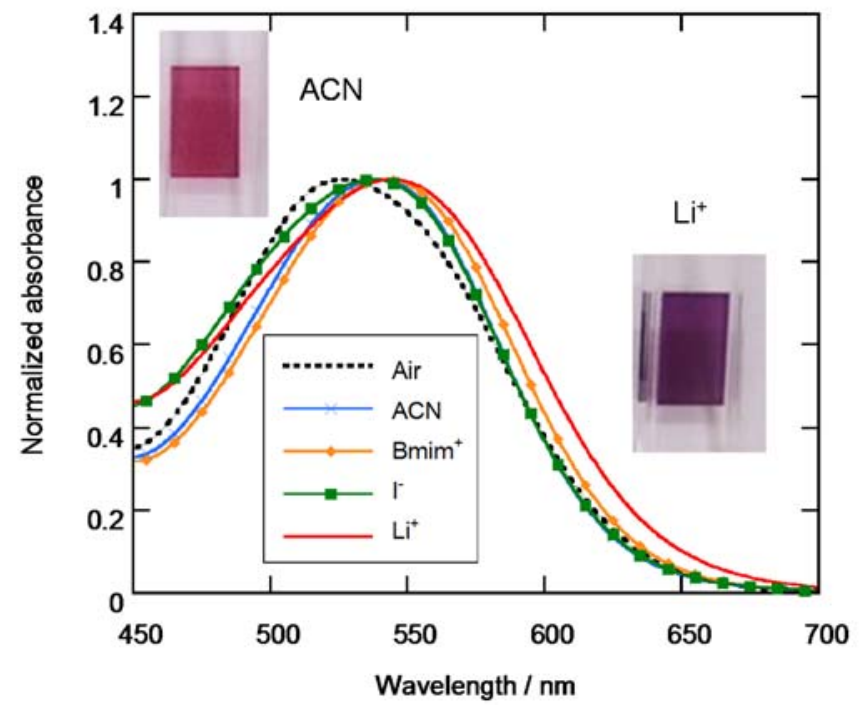

Fig. 3

Absorption spectra of $\mathrm{D}_{149 / \mathrm{TiO}_{2}}$ in air (Air), acetonitrile (ACN), $0.3 \mathrm{M}$ 1-butyl-3-methylimidazolium bis(trifluoromethanesulfonyl)imide in $\mathrm{ACN}\left(\mathrm{Bmim}^{+}\right), 0.3 \mathrm{M}$ tetrabutylammonium iodide in $\mathrm{ACN}\left(\mathrm{I}^{-}\right)$, and $0.3 \mathrm{M} \mathrm{LiClO}_{4}$ in $\mathrm{ACN}\left(\mathrm{Li}^{+}\right)$. 


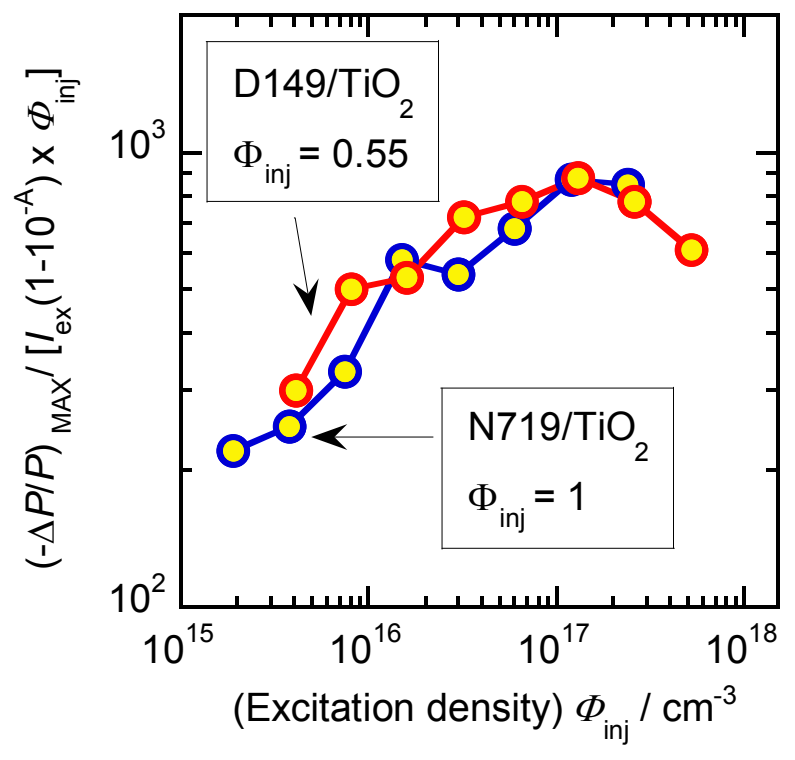

Fig. 4

$(-\Delta P / P)_{\text {MAX }}$ normalized by $\left(I_{\mathrm{ex}}\left(1-10^{-A}\right) \Phi_{\mathrm{inj}}\right)$ as a function of (excitation density $) \Phi_{\mathrm{inj}}$. 


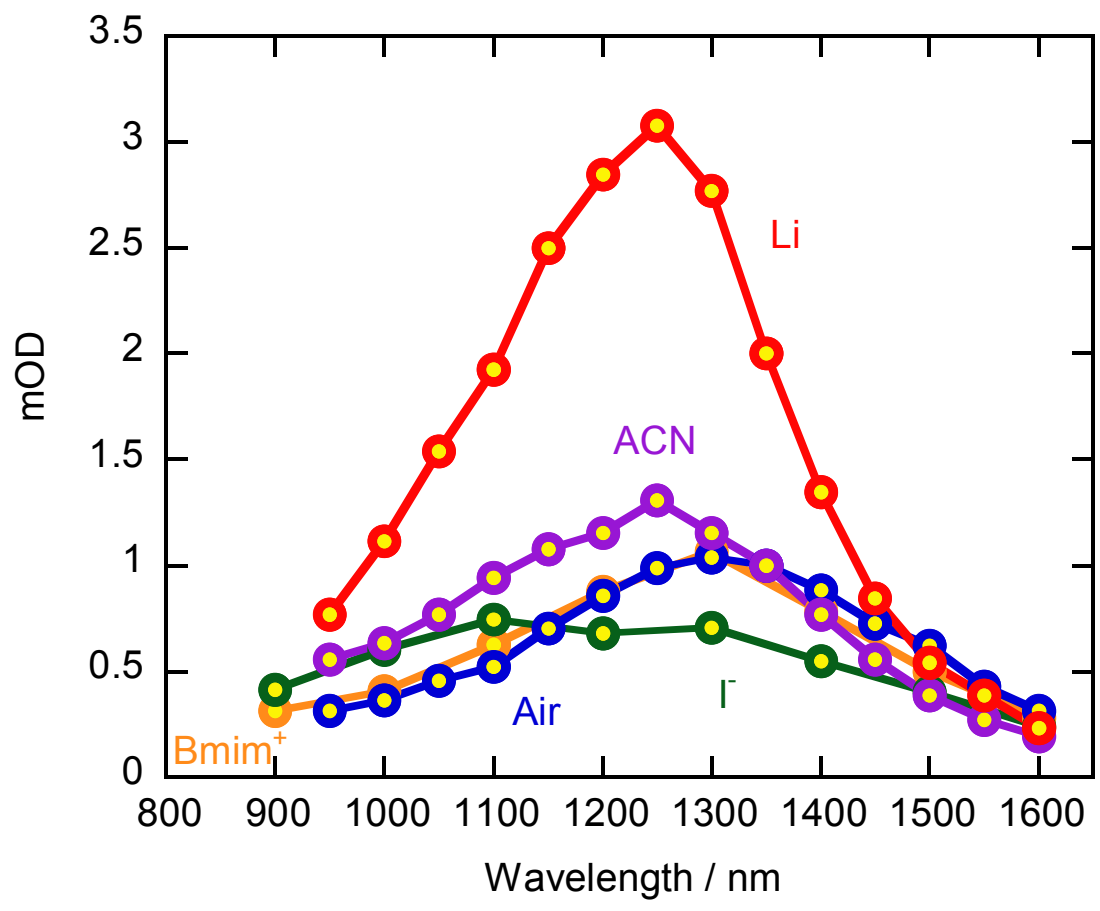

Fig. 5

Transient absorption spectra of $\mathrm{D} 149 / \mathrm{TiO}_{2}$ just after excitation in air (Air), acetonitrile (ACN), 0.3 M 1-butyl-3-methylimidazolium bis(trifluoromethanesulfonyl)imide in $\mathrm{ACN}\left(\mathrm{Bmim}^{+}\right), 0.3$ $\mathrm{M}$ tetrabutylammonium iodide in $\mathrm{ACN}\left(\mathrm{I}^{-}\right)$, and $0.3 \mathrm{M} \mathrm{LiClO}_{4}$ in $\mathrm{ACN}\left(\mathrm{Li}^{+}\right)$. 


\section{Graphical Abstract}

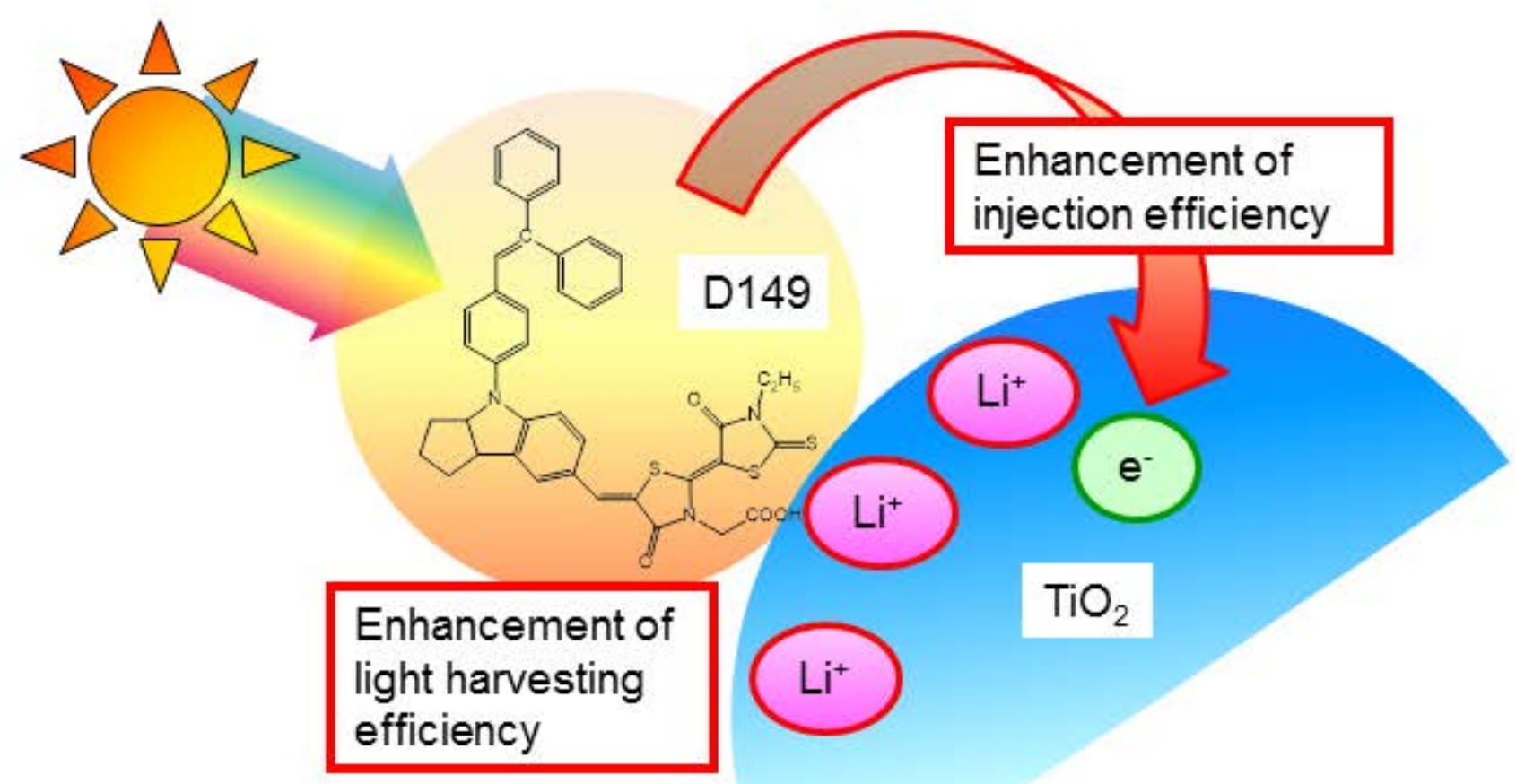

